\title{
Anguillicola papernai (Nematoda: Anguillicolidae) and other helminths parasitizing the African longfin eel Anguilla mossambica
}

\author{
H. Taraschewski ${ }^{1, *}$, J. Boomker ${ }^{2}$, K. Knopf ${ }^{3}$, F. Moravec ${ }^{4}$ \\ ${ }^{1}$ Universität Karlsruhe, Zoologisches Institut - Ökologie/Parasitologie, Kaiserstrasse 12, 76128 Karlsruhe, Germany \\ ${ }^{2}$ Department of Veterinary Tropical Diseases, University of Pretoria, Private Bag X04, 0110 Onderstepoort, \\ Republic of South Africa \\ ${ }^{3}$ Institute of Freshwater Ecology and Inland Fisheries, Müggelseedamm 310, 12587 Berlin, Germany \\ ${ }^{4}$ Czech Academy of Sciences, Institute of Parasitology, Branišovská 31, 37005 České Budějovice, Czech Republic
}

\begin{abstract}
The swim bladder nematode Anguillicola papernai Moravec \& Taraschewski, 1988 has been investigated as regards its occurrence in longfin eels Anguilla mossambica (Peters) in rivers in South Africa. A. papernai revealed a prevalence of around $50 \%$ and a mean intensity of about 6 adult worms at 1 sampling site but were less abundant in 3 others. Field observations suggest a more narrow habitat preference than that of Anguillicola crassus and a seasonal pattern of abundance. African longfin eels harboured a poor helminth community. In addition to A. papernai, 2 gastro-intestinal nematodes occurred, the stomach worm Heliconema longissimum Ortlepp, 1923 as the dominant species, and the intestinal Paraquimperia africana Moravec, Boomker \& Taraschewski, 2000. Experiments were undertaken using European eels Anguilla anguilla (Linnaeus) and copepods as laboratory hosts. The morphology of larvae and adult parasites obtained from these experimental hosts is described. The ultrastructure of adult worms recovered from wild longfin eels was studied. The 'papilla-like excrescences of fibrous structure' on the adult worms' cuticle, as mentioned in the original description, are in fact the attachment points of thick cords of fibers interconnecting the epicuticle with the hypodermis. Such a structure has not yet been described from any other species of Anguillicola Yamaguti, 1935. At present in South Africa, Mozambique and Madagascar attempts are on the way to establish an eel management like in Asia and Europe including eel farming. In this context, care should be taken to prevent the introduction of non-endemic eel parasites into Africa and Madagascar. On the other hand, the future commercial management of African eel species should not lead to the spread of A. papernai or other parasites of African eel species to Europe or elsewhere. In this study $A$. papernai has been experimentally demonstrated to be capable of reproducing in the European eel and of using European copepods as intermediate hosts.
\end{abstract}

KEY WORDS: Anguilla mossambica $\cdot$ Eel $\cdot$ Anguillicola papernai $\cdot$ Swim bladder $\cdot$ Copepods $\cdot$ Life cycle $\cdot$ Morphology $\cdot$ Ultrastructure $\cdot$ Eel culture

\section{INTRODUCTION}

The genus Anguillicola Yamaguti, 1935, the members of which infect the swim bladders of eels, had attracted little attention until A. crassus Kuwahara, Niimi \& Itagaki, 1974, known from Anguilla japonica
Temminck \& Schegel and cultured Anguilla anguilla (Linnaeus) in East Asia (Nagasawa et al. 1994, appeared in Europe in the 1980s. First occurring in the German river Weser (Neumann 1985), it quickly spread to populations of the European eel A. anguilla throughout Europe and North Africa, and finally 
reached North America, where it infected Anguilla rostrata (Lesueur) (Barse \& Secor 1999, Maamouri et al. 1999, Knopf et al. 2000). It turned out to be highly pathogenic in European eels, which led to considerable public interest (Würtz \& Taraschewski 2000). In the meantime, however, it is discussed whether wild European eels somehow have become adapted to chronic parasitism by Anguillicola crassus (Kelly et al. 2000).

Moravec \& Taraschewski (1988) compiled and partly described 5 Anguillicola species parasitizing in different eel species in different regions of the world, namely A. crassus, A. globiceps Yamaguti, 1935, A. australiensis Johnston \& Mawson, 1940, Anguillicola novaezelandiae Moravec \& Taraschewski, 1988 and Anguillicola papernai Moravec \& Taraschewski, 1988. Unlike A. crassus, the other Anguillicola species have been little studied (Moravec et al. 1994, Kennedy 1995, Lefèbvre et al. 2004). This is especially true for $A$. papernai which has been recorded only once in Anguilla mossambica (Peters) near East London, Eastern Cape Province, South Africa, leading to the first description of the parasite (Moravec \& Taraschewski 1988).

The aim of this investigation was to gather information on the prevalence, abundance, habitat preference and life cycle of this nematode, as well as its morphology, including that of the larvae. Furthermore, we wanted to know with which other helminths it concurrently occurs in populations of Anguilla mossambica. The data presented in this paper are all we know about
Anguillicola papernai thus far. The field studies were intended to be continued over the following years, but as it became increasingly difficult to obtain eels sampled in the vicinity of East London or at other sites in South Africa we decided to publish our data now, without any potential further supplementation.

\section{MATERIALS AND METHODS}

Collection localities. The sampling Stns 1 to 3 belong to the area around the city of East London (Eastern Cape Province). The first sampling site on the Nahoon River is situated about $10 \mathrm{~km}$ away from its mouth, i.e. the Indian Ocean, and is surrounded by diversely structured, extensively managed farmland with no human settlements close by ('Nahoon Farmland', Table 1). At the angling site the river formed a basin of about $15 \mathrm{~m}$ in width edged by steep rocks with trees on one side, and reeds and meadows on the other. This site was sampled only once during March 1994.

The second sampling site ('Nahoon Reservoir', Table 1) is about $4 \mathrm{~km}$ upstream of the first one, at the point where the Nahoon River is dammed up by a high concrete wall. Beneath this obstacle, which prevents upstream migration of fish, the river forms a pond surrounded by reeds, rocks and gravel. Prior to sampling, water was released from the dam in order to simulate rainfall and to create turbidity. This site was sampled twice, during March 1994 and January 1995.

Table 1. Anguilla mossambica. Field data and data on helminth parasites collected during 2 expeditions and at 3 sampling sites. nd: not determined; SD: standard deviation (in brackets)

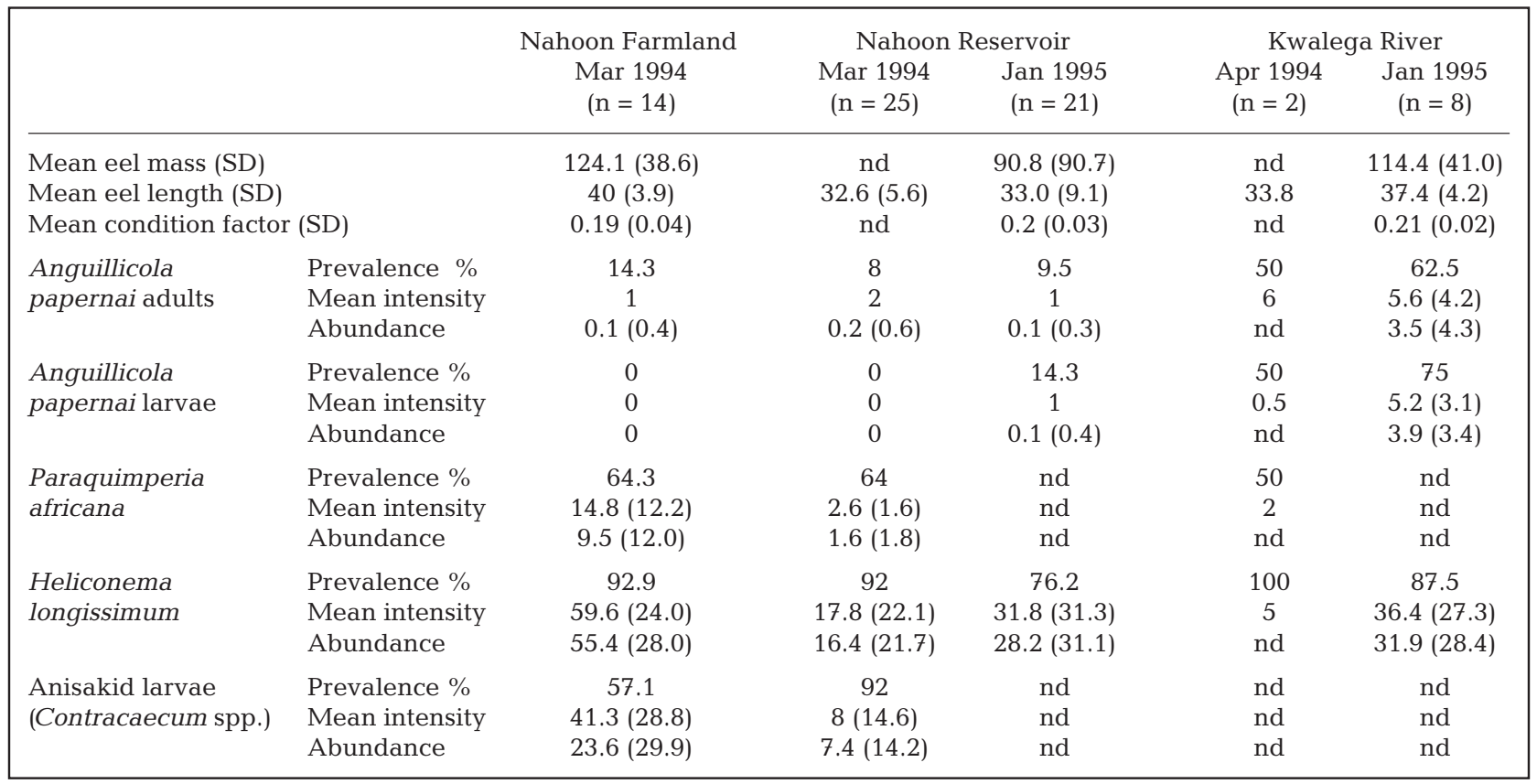


The Kwalega River, the third sampling site, is only half as wide as the Nahoon River, and because of the steeper slope, the current is stronger. The substrate is coarse, consisting mainly of rocks and sharp gravel. The sampling site was located on farmland with bushes about $2 \mathrm{~km}$ away from the coast and about 15 to $20 \mathrm{~km}$ northeast of the mouth of the Nahoon River. This site was also sampled twice, during April 1994 and January 1995.

A single longfin eel, $50.5 \mathrm{~cm}$ long and $345 \mathrm{~g}$ in mass, was collected from the Sabie River inside the Kruger National Park near the border to Mozambique during April 1994. No helminths were recovered.

Sampling and dissection of eels. Longfin eels $(\mathrm{n}=$ 70) as well as Mozambique mottled eels Anguilla marmorata Quoy \& Gaimard $(\mathrm{n}=2)$ were sampled. The eels were caught with baited handlines which, in the Eastern Cape Province, is successful only after heavy rain, usually between October and March (D. Radloff pers. comm.). Attempts to catch eels during the dry seasons failed, as did trapping them in an imported eel trap.

The caught eels were kept alive in insulated containers and brought to a laboratory at the Amalinda Fish Research Station in East London. They were housed overnight in large oxygenated tanks and dissected after decapitation the next morning. Mass and length were determined, whereafter the swim bladder was removed and examined for the presence of Anguillicola papernai. The opened swim bladder was examined between 2 plexiglas plates for histotropic $L_{3}$ and $\mathrm{L}_{4}$ stages using a stereoscopic microscope with light from underneath. The entire alimentary canal was removed and divided into stomach and intestine, which were opened in separate Petri-dishes containing phosphate buffered saline, and examined for helminths under a stereoscopic microscope. The same was done with the gills and the remaining viscera. Squash preparations of muscle, kidney and heart, however, were not made and the eyes were not examined.

Processing of the helminths. For light microscopical studies the nematodes were fixed in either boiling or cold $70 \%$ ethanol and preserved in $70 \%$ ethanol. Helminths were cleared in 50\% lactophenol in water and drawings were made with the aid of a Zeiss drawing tube. For scanning (SEM) and transmission electron microscopy (TEM) the specimens were processed using standard methods. Semi-thin sections of Anguillicola papernai were cut with a Reichert ultramicrotome, stained with methylene blue, and examined and photographed with a Zeiss Axiophot photomicroscope. The SEM-examination was done with a Cambridge S4/10 and TEM with a Phillips CM 200.

Experiments on the life cycle of Anguillicola papernai. Swim bladders of heavily infected eels from the Kwalega River, Eastern Cape Province, were rinsed with tap water into an aquarium containing unidentified copepods, collected from a pond in Gauteng Province, South Africa, and fed on suspended yeast. After the copepods had been allowed to feed on the $\mathrm{L}_{2}$ stages washed from the swim bladders, they were kept outdoors for 2 wk at approximately $20^{\circ} \mathrm{C}$. The copepods were transferred to Germany and after another 2 wk of laboratory maintenance under the same conditions as in South Africa, the copepods were force-fed with a stomach tube (Knopf et al. 1998) to 2 A. crassus-free European eels purchased from an eel farm (Limnotherm, Bergheim). The eels were kept together at $20^{\circ} \mathrm{C}$ in an 801 aerated aquarium with 2 polypropylene tubes serving as hiding places. The individuals were force-fed twice an week with pelleted food supplied by the eel farm.

A year later (360 d post-infection) 1 eel was killed by decapitation, and its swim bladder was opened and examined for adult and larval Anguillicola papernai. The second eel was killed on Day 415 post-infection (pi). The bottom of the aquarium where the eels were kept was inspected for $\mathrm{L}_{2}$ of the parasite once a month by pipetting sediment into a Petri-dish, which was subsequently examined under a stereoscopic microscope. In the fifth month pi sufficient larvae were obtained from the aquarium to infect the copepods Thermocyclops cf. crassus (Fischer) and Mesocyclops leuckarti (Claus), collected from a pond in the Botanical Garden of the University of Karlsruhe and thus free of $A$. crassus or any other helminth infection. The copepods were placed in a $40 \mathrm{l}$ aquarium and allowed to feed on the $\mathrm{L}_{2}$ larvae collected from the aquarium the eels were kept in. From the 3rd day after adding the nematode larvae, the copepods were fed with suspended yeast and remained in the same aquarium at $20^{\circ} \mathrm{C}$ until they were used to infect eels, 30 d later. Three individuals were infected by stomach tube and kept in separate aquaria under conditions as described above. Eel 1 received an undetermined number of larvae, still inside the copepods, the second was given 20 larvae liberated from copepods, and 9 larvae were given to Eel 3. Eel 1 was killed 131 d post-infection (dpi) and Eel 2 on Day 275 pi Eel 3 died 7 dpi.

Adult Anguillicola papernai collected from experimentally infected European eels as well as larvae obtained from the laboratory cycle were prepared for measurements as described above.

The maintenance of eels and copepods infected with Anguillicola papernai in the laboratory in Germany as well as all related experiments were carried out under strict laboratory preventive measures. Water potentially containing $\mathrm{L}_{2}$ larvae of the parasite was prevented from getting into the public sewage system. 


\section{RESULTS AND DISCUSSION}

\section{Field observations}

Only 2 of the 14 long fin eels from the site 'Nahoon Farmland' were infected with 1 Anguillicola papernai each. Larvae could not be detected in the swim bladder wall (Table 1). Beside A. papernai, 3 other species of nematodes were recorded: Paraquimperia africana Moravec, Boomker \& Taraschewski, 2000, inhabiting the small intestine, Heliconema longissimum Ortlepp, 1923 in the stomach, as well as Contracaecum spp., encapsulated on virtually all surfaces of the viscera (Table 1). H. longissimum was most prevalent and most abundant. The few data available did not permit any appreciable statistical analyses.

The 2 specimens of Anguilla marmorata also caught at this station in March (length 87 and $55 \mathrm{~cm}$, weight 2001 and 287 g, respectively) harboured only Contracaecum larvae on the outer surfaces of their viscera.

At the second sampling site ('Nahoon Reservoir') in March and January the prevalence of adult Anguillicola papernai approximated 10\% (2 eels out of 25 and 21 , respectively, being infected). In January, however, the larval prevalence was $14 \%$ as opposed to the $0 \%$ in March at both the Nahoon sampling sites. The abundance of adult worms was as low as at the other Nahoon station. The dominant species, Heliconema longissimum, did not show the same high worm burdens as at the farmland station further downstream (Table 1) but this seemed to be due to the smaller average eel size below the dam. The lower abundance and intensity of Paraquimperia africana as well as of the anisakid larvae also might reflect the lower length of the eels at the Nahoon Reservoir compared to the farmland station.

Approximately 5 Anguillicola papernai were present in the swim bladder of about every second of the 10 individuals from the Kwalega River. The maximum intensity was 12 adult nematodes per eel. These preliminary infection data reveal a high degree of overdispersion in this river. In contrast to the Nahoon sites a strong presence of larvae was noted, especially in January. The occurrence of the 3 other helminth species resembled the situation in the Nahoon River (Table 1).

The difference in occurrence of Anguillicola papernai in the 2 rivers might reflect a specific habitat preference of the parasite, or its intermediate hosts. The Kwalega River is fast-flowing whereas the Nahoon has a weak current only, but the available data are too limited for a discussion of this nature. In addition, the data seem to suggest a certain seasonality in the occurrence of the parasite. At all 3 stations an increase of larvae, presumably due to new infections, was noted in January.

The prevalence, as well as the worm burden of Anguillicola papernai, resembles the situation which has been described for the other Anguillicola species in their indigenous eel hosts. In Queensland, Australia, the overall prevalence of A. australiensis in Anguilla reinhardtii (Steindachner) was $50 \%$ and reached $78 \%$ in 1 of 9 locations, but the intensity nowhere exceeded 10 worms per swim bladder (Kennedy 1994). Similar data are available for Anguillicola globiceps in Anguilla japonica from 2 sites in China and 1 in Japan. At the former locality the prevalence was 40 and $61 \%$, respectively, and the intensity ranged between 1 and 12 ; in the latter a prevalence of $6 \%$ was found, and the incidence was mostly 3 or 4 (maximum 7 ) adult worms per swim bladder (Wang \& Zhao 1980, Nagasawa et al. 1994). Even Anguillicola crassus in its indigenous host, Anguilla japonica, revealed a similar prevalence during different surveys $(25,40,17.5,56 \%$ ) (Nagasawa et al. 1994). A maximum intensity of 11 adult worms was recorded. In East Asia it is only in cultured European eels that this species occasionally reaches a $100 \%$ prevalence and a maximum intensity exceeding 30 (Nagasawa et al. 1994).

After its introduction into Europe, infection rates of Anguillicola crassus reached almost $100 \%$ in European eels (Taraschewski et al. 1987, Kennedy \& Fitch 1990, Thomas \& Olivier 1992) with mean intensities of adult worms often above 20 (Thomas \& Olivier 1992) and maximum worm burdens of 42 (Taraschewski et al. 1987) or 71 (Cardoso \& Saraiva 1998) adults per individual. Similar data have been published concerning another phylogenetically young host-parasite relation, i.e. A. novaezelandiae in Anguilla anguilla in a lake near Rome where the nematode had been introduced from New Zealand in the early 1980s. Here the prevalence was $80 \%$, the intensity 1 to 27 and the mean 11 (Moravec et al. 1994). In contrast, in its natural host Anguilla australis in New Zealand the prevalence ranged from 0 to $12 \%$ (5 biotopes) with intensities of 1 or 2 adult worms (maximum: 5) (Lefèbvre et al. 2004).

Thus, the field data presented in this study suggests that Anguilla mossambica and Anguillicola papernai have come to a state of moderate host-parasite relations after long co-evolution.

The 2 other nematode species found as adults in the digestive tracts of African longfin eels and reported on in this paper are eel-specific, as is Anguillicola papernai (Moravec et al. 2000, Ogden 1969, Chabaud 1989). The stomach worm Heliconema longissimum was always the dominant species in Anguilla mossambica.

Low parasite diversity and high dominance as reported here from an African eel species are also known from populations of European eels (Kennedy et al. 1998, Sures et al. 1999) as well as from American eels Anguilla rostrata in Canada (Cone et al. 1993, Barker et al. 1996, Marcogliese \& Cone 1996). So far, only a survey on macroparasites in and on $A$. rein- 
Table 2. Anguillicola papernai from experimentally infected Anguilla anguilla. Measurements in mm of fixed adults. dpi = days post-infection

\begin{tabular}{|c|c|c|c|}
\hline Criterion & Males, 131 dpi $(n=6)$ & Gravid females, 131 dpi $(n=4)$ & Gravid females, 275 dpi $(\mathrm{n}=3)$ \\
\hline Body length & $14.24-20.66$ & $13.70-14.86$ & $20.40-24.07$ \\
\hline Max. body width & $1.17-1.43$ & $1.30-3.33$ & $2.24-2.58$ \\
\hline \multirow{2}{*}{ Buccal capsule length } & $0.012-0.015$ & 0.012 & 0.012 \\
\hline & 0.027 & $0.027-0.030$ & $0.027-0.030$ \\
\hline \multirow[t]{2}{*}{ Cephalic end length } & $0.095-0.018$ & $0.109-0.135$ & 0.095 \\
\hline & $0.105-0.109$ & $0.095-0.108$ & Not determined \\
\hline Width of neck constriction & $0.095-0.099$ & $0.093-0.108$ & $0.122-0.136$ \\
\hline \multirow[t]{2}{*}{ Oesophagus length } & $0.476-0.530$ & $0.517-0.558$ & $0.598-0.612$ \\
\hline & $0.136-0.150$ & $0.150-0.163$ & $0.150-0.204$ \\
\hline $\begin{array}{l}\text { Ratio: oesophagus length } \\
\text { to body length }\end{array}$ & $1: 30-39$ & $1: 25-28$ & $1: 33-37$ \\
\hline Nerve ring & $0.153-0.180$ & $0.129-0.138$ & $0.122-0.136$ \\
\hline Vulva from posterior end & Not applicable & $2.52-3.20$ & $2.60-5.10$ \\
\hline Length of tail & Not determined & 0.299 & $0.245-0.299$ \\
\hline Remarks & Not applicable & $\begin{array}{c}\text { Numerous eggs, larvae not yet } \\
\text { developed }\end{array}$ & $\begin{array}{l}\text { Numerous eggs with } \\
\text { developed } \mathrm{L}_{2}\end{array}$ \\
\hline
\end{tabular}

hardtii in Queensland (tropical Australia) has revealed very rich parasite communities (Kennedy 1995). This study did not, however, determine whether the parasites were in a reproductive stage. In the study by Sures et al. (1999) about $50 \%$ of the helminths of $A$. anguilla in the Rhine River were neozoic species of non-European origin reflecting the enormous imports of non-European eels into Europe. In contrast, the very poor helminth communities of longfin eels in South Africa do not reveal any allochtonous impact. Among the adult helminth species recorded here from $A$. mossambica, only Heliconema longissimum was described from other eel species. However, the taxonomy of the genus Heliconema is confusing and is currently being revised by F. Moravec et al. (unpubl.).

\section{Morphology of adult worms}

The measurements of the 13 adult worms derived from experimental infections in the European eel (Table 2) closely resemble those presented in the original description of Anguillicola papernai based on 4 females and 1 male specimen from naturally infected longfin eels (Moravec \& Taraschewski 1988). The range of measurements is wider in the present individuals.

Fig. 1. Ink drawings of Anguillicola papernai Moravec \& Taraschewski, 1988, from experimentally infected European eels and copepods. Scale bars in mm. (A, B) Gravid female. (A) Anterior end of body; (B) cephalic end. Note the knobs on the outer surface. (C-F) Third-stage larva from the copepod intermediate host. (C) Anterior end, dorso-ventral view; (D) same, lateral view; (E) general view of larva; (F) tail. (G, H) Free second-stage larvae

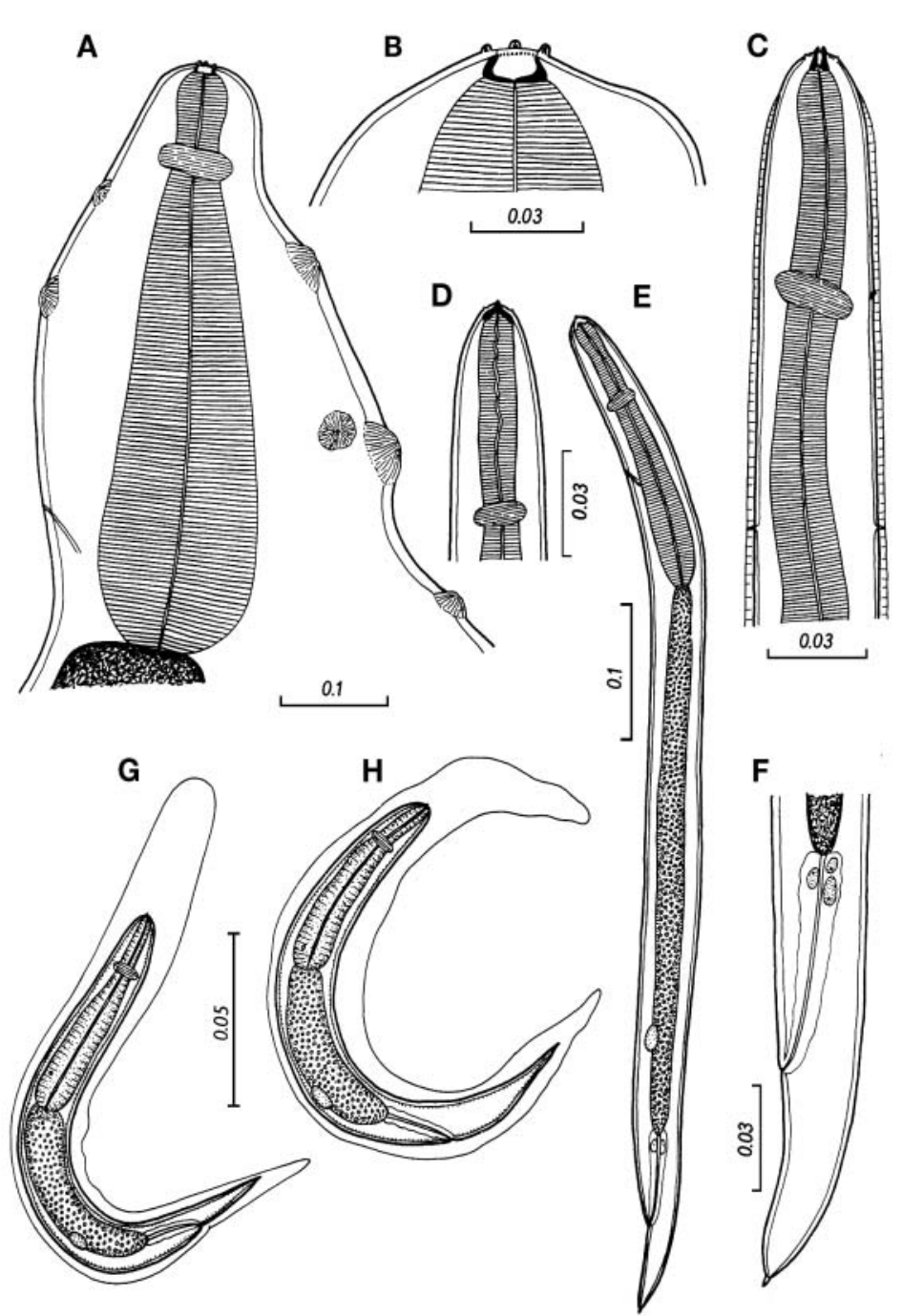




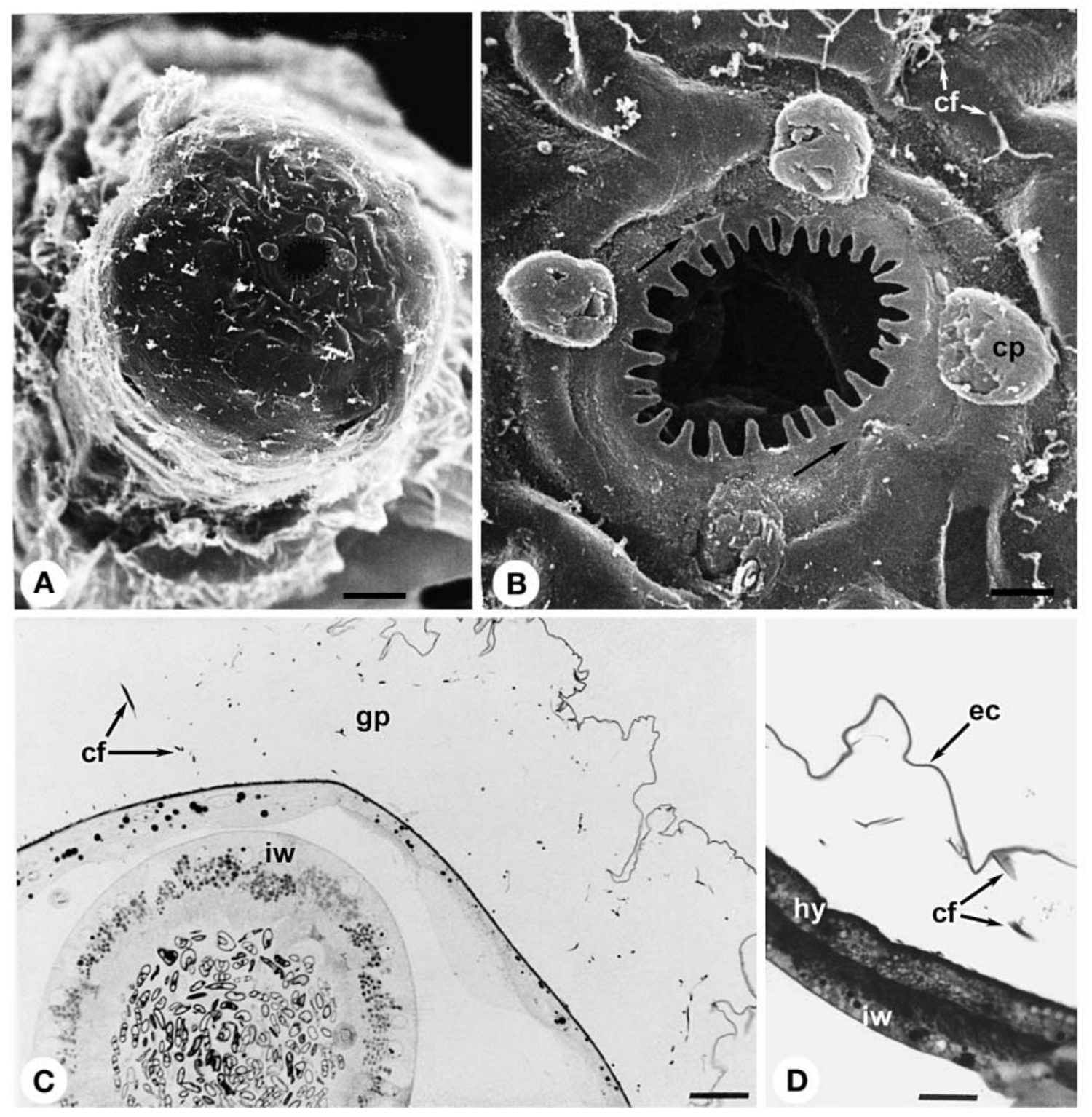

Fig. 2. Anguillicola papernai from naturally infected Anguilla mossambica. Micrographs showing external features of adult. $(\mathrm{A}, \mathrm{B})$ Scanning electron micrographs of the buccal (A) and oral (B) region. Note the 26 (27) oral teeth, and the large dorsolateral cephalic papillae (cp); the 2 lateral amphids (arrows) are very indistinct, also the filiform outgrowths (cf) of the hypodermis' outer surface, persisting on the surface after the gelatinous outer part of the cuticle was washed away during the SEM-preparation of the worm. Scale bars: $(A)=15 \mu \mathrm{m},(B)=3 \mu \mathrm{m}$. (C) Semi-thin section through the body wall. At the mid and posterior part of the body the outer gelatinous part of the cuticle (gp) may be very thick and interspersed with filiform cords of fibres (cf); iw: intestinal wall. Scale bar $7 \mu \mathrm{m}$. (D) Semi-thin section of the intestinal wall (iw), hypodermis (hy) and cuticle. Note the medium-sized cord of fibers (cf) communicating with the epicuticle (ec) and obviously keeping the latter in position. Scale bar $=8 \mu \mathrm{m}$

The main difference is that the buccal capsule is not as deeply retracted into the body as in the type specimens (Figs. $1 \& 2 \mathrm{~A}, \mathrm{~B}$ ); this probably has to do with the method of fixation. The surface structures named cuticular 'papilla-like excrescences of fibrous structure' (Fig. 1A) in the paper by Moravec \& Taraschewski (1988) which are present on the narrower anterior and posterior parts of the worms, were again studied by light microscopy. In the present investiga- tion, however, these structures appeared to be less numerous and less conspicuous which, again, may have to do with the method of fixation. When these structures, together with the cuticle, are viewed with the electron microscope, it is evident that most of the cuticle consists of a gelatinous matrix and that the 'excrescences' mark the points of attachment of thick cords of fibres that interconnect the epicuticle with the outer membrane of the hypodermis (Fig. 2D). 

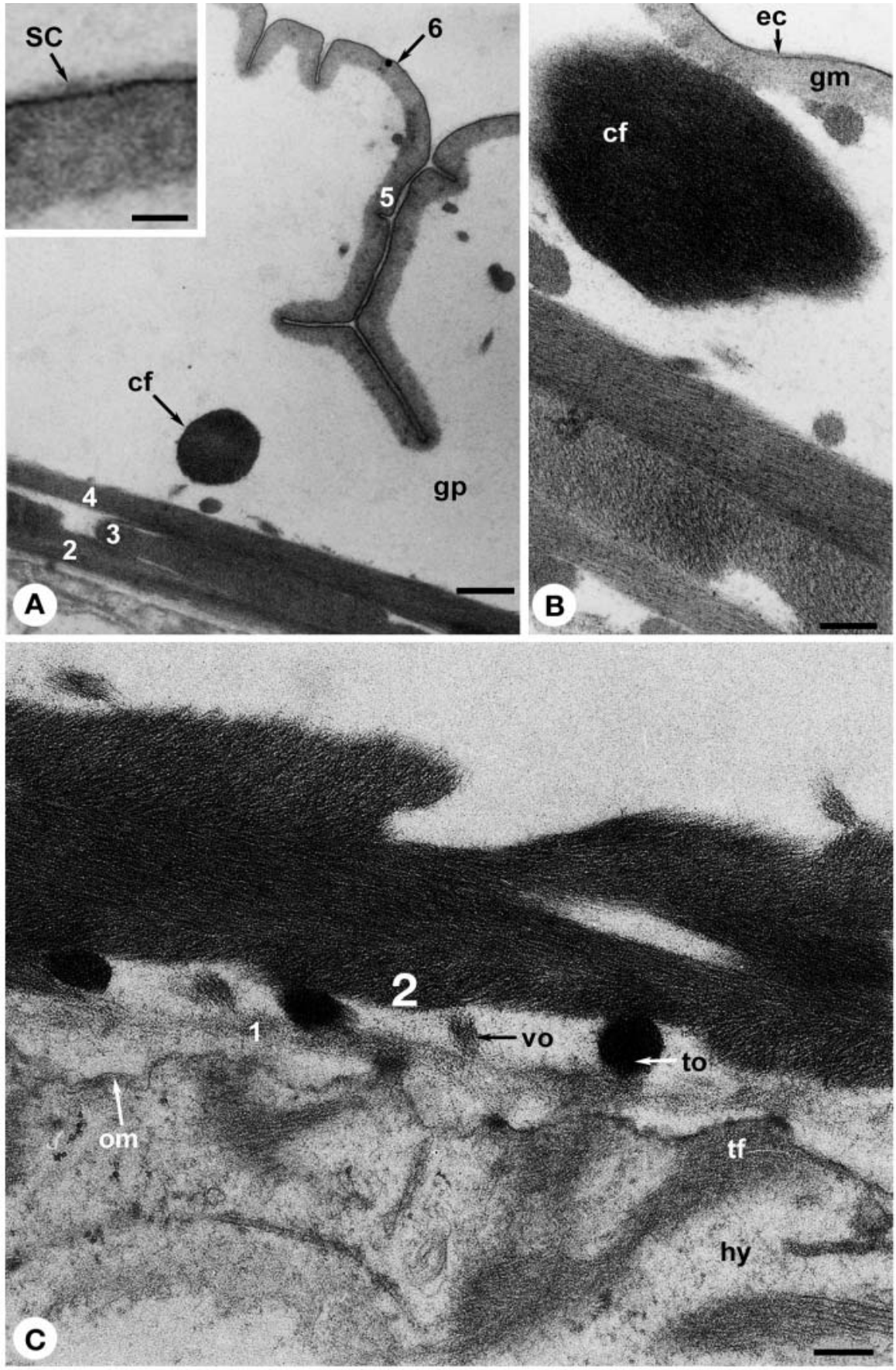

Fig. 3. Anguillicola papernai from naturally infected Anguilla mossambica. Transmission electron micrographs of cross sections through cuticles and hypodermes of adult. (A) Note the regular arrangement of 3 prominent layers of fibre cords (2-4) in the inner part of the cuticle. The innermost thin, less compact layer of fibres (1) cannot be seen well in (A). It can be discerned better in (C). In the gelatinous outer part of the cuticle (gp) a medium-sized filiform radially arranged cord of fibres (cf) can be seen. The epicuticle (6th electron-dense layer) is supported on its inner side by granular matter of a considerable thickness (Layer 5). Scale bar = $0.5 \mu \mathrm{m}$. Inset: higher magnification of the worm's outer surface (Layers 5 and 6 ) showing the fuzzy surface coat (sc). Scale bar $=$ $0.15 \mu \mathrm{m}$. (B) Obliquely sectioned very thick rope (cf) inside the gelatinous layer of the cuticle. The attachment site of such a thick cord of filaments at the epicuticle (ec) is seen as a knob (compare Fig. 1A) when the worm is viewed by a light microscope; gm: granular matter underneath the epicuticle. Scale bar $=0.25 \mu \mathrm{m}$. (C) At high magnification a circularly oriented thin layer of loosely arranged fibers (1) between the hypodermis (hy) and the inner circularly oriented cord (2) of fibres can be discerned. This layer as well as the overlying 3 layers of differently oriented fibers $(2-4$, compare A) are interwoven by radially arranged, regularly set thin outgrowths (to) and very thin outgrowths (vo) of the hypodermis' outer membrane (om). The points of insertion at the outer membrane (om) are supported by tonofilaments (tf) inside the hypodermis. Scale bar $=0.2 \mu \mathrm{m}$ 
The cuticle may reach considerable thickness, especially at the mid and posterior part of the worm's body (Fig. 2C). Six layers of electron-dense matter can be distinguished in the gelatinous electronlucent matrix that forms the major portion of the cuticula (Figs. 2C,D, 3). Close to the outer membrane of the hypodermis, 4 layers of fibrous matter, can be differentiated. The innermost one (Layer 1) is rather thin with loosely associated fibres that do not show a clear spatial orientation (Fig. 3C). Towards the exterior it is followed by 3 layers of compact fibre cords (Fig. 3). The inner one of these 3 (Layer 2) consists of strands which are ovoid in cross section and are arranged like circular belts around the worms. In the second one (Layer 3) the strands form a belt of longitudinally arranged cords. In the outermost layer (Layer 4) the cords show again the same arrangement and structure as in Layer 2. The fibres inside the cords reveal different orientations. Between the cords of each of the 3 fibrous belts the gelatinous matrix of the cuticle remains visible (Fig. 3). The outer lining of the cuticle is formed by a monolayered, osmiophilic epicuticle (Layer 6), which is interiorly supported by a thick layer (5th electron-dense layer) consisting of granular matter (Fig. 3). A surface coat (glycocalyx) can be figured out at higher magnification (Fig. 3A inset).

In addition to the epicuticle with its thick lamina and the layers of fibre cords in the inner part of the gelatinous cuticle, a system of more or less radially arranged cords of filaments contributes to the stability of the gelatinous cuticle (Figs. 2 \& 3). These 'spokes' seem to keep the epicuticle in position. They originate from the outer membrane of the hypodermis and are supported by bundles of tonofilaments inside the hypodermis. It appears that each size group of cords follows a regular pattern of position on the surface of the hypodermis (Fig. 3C). They seem to be interwoven with the thin innermost layer of fibrous matter (Layer 1) and the thick 3-layered fibre belt (Layers 2 to 4 ) further outwards by passing through the open spaces between the cords of these layers. The diameter of these radially arranged 'spokes' may vary considerably, between about $0.02 \mu \mathrm{m}$ and $1.4 \mu \mathrm{m}$.

At least the thin and very thin bundles of fibres seem to form a regular pattern along the hypodermis (Fig. 3C) while the few medium-sized (Fig. 3A) and thick ones (Fig. 3B) do not seem to follow a specific pattern. Accordingly, the points of their attachment at the epicuticle do not show a regular distribution and thus the knobs on the surface of the nematodes, as seen by light microscopy, do not follow a pattern (Fig. 1 and also see Fig. 7 of Moravec \& Taraschewski 1988). In specimens of Anguillicola papernai that were prepared for scanning electron microscope (SEM) investigation, large portions of the gelatinous matter (as well as the epicuticle) were washed away, especially near the mouth opening where the cuticle is generally thin. At the surface of such worms the strings that formerly kept the epicuticle in position can still be discerned (Fig. 2A,B: thin or very thin strings are seen).

The knobs on the surface of Anguillicola papernai have not been described from the other Anguillicola species (Moravec \& Taraschewski 1988), suggesting that the other species are not equipped with the thick cords of fibres described here. After fixation in alcohol, the gelatinous part of the cuticle seems to shrink, making the points of attachment of the thick cords appear as prominent excrescences. Cords of smaller diameter were shown in micrographs of 2 studies on A. crassus (Taraschewski et al. 1988, Kirk et al. 2002). In the ultra-thin sections of $A$. papernai studied here, the epicuticle is seen as a single osmiophilic, monolayered lamella. In contrast, the outer lining of $A$. crassus has been interpreted as a 'multilayered epicuticle' (Taraschewski et al. 1988) or as a 'multilayered network of filaments, overlying a densely stained osmiophilic membrane' (Kirk et al. 2002). However, in Fig. $2 \mathrm{C}$ of the latter paper the 'filaments' reveal the same thickness as the cuticle itself although they are less osmiophilic. This labyrinthine surface is probably useful in molecular mimicry or in resistance against the host's defense or the chemical environment inside the swim bladder. We do not know why the worms investigated in our study were lacking such an enlarged surface, but it appears unlikely that the labyrinth got lost during the shipment of the fixed nematodes from South Africa to Germany, since the epicuticle of these specimens still carried a surface coat. Such a glycocalyx rich in carbohydrates has been demonstrated from many parasitic nematodes (Dell et al. 1999).

Other morphological differences between Anguillicola crassus and A. papernai can be seen by SEM: in A. papernai the number of the circumoral teeth seems to be around 26 to 27 (Fig. 2B and see also Fig. $7 \mathrm{~F}$ of the paper by Moravec \& Taraschewski 1988) whereas $A$. crassus usually only possesses 22 or fewer, only exceptionally having up to 28 teeth. (Taraschewski et al. 1987, Moravec \& Taraschewski 1988). The size of the buccal capsule in fully developed $A$. crassus is distinctly larger $(20-27 \times 40-63 \mu \mathrm{m})$ (but only $12-15 \times$ 33-42 $\mathrm{mm}$ in juvenile forms) as compared to that of fully developed $A$. papernai $(9-15 \times 27-30 \mu \mathrm{m})$. Furthermore, the cephalic papillae seem to be considerably larger in A. papernai (Fig. 2B) than in A. crassus (Taraschewski et al. 1987: Fig. 3C; H. Taraschewski, J. Boomker, F. Moravec unpubl.). 


\section{Larval morphology}

The larvae of Anguillicola papernai have not yet been described. The following descriptions were made from larvae obtained in the laboratory from experimental infections in Anguilla anguilla and in European copepods.

\section{Free second-stage larvae}

Free second-stage larvae are sheathed by the cuticle of the first moult. They are elongate, whitish to translucent, 0.177 to $0.192 \mathrm{~mm}$ long and $0.018 \mathrm{~mm}$ wide. The cuticular sheath is 0.030 to $0.033 \mathrm{~mm}$ wide. The cephalic end is armed with a minute dorsal conical cuticular tooth. The cuticle is very thin and smooth. The internal organization of the body is not clearly visible. The oesophagus is 0.051 to $0.075 \mathrm{~mm}$ long, with a somewhat expanded posterior part. The nerve ring encircles the oesophagus 0.021 to $0.027 \mathrm{~mm}$ from its anterior end. The excretory pore was not seen. The intestine is relatively wide, sparsely granulated; the rectum is a thin-walled, colourless tube. The tail is conical, sharply pointed, 0.039 to $0.060 \mathrm{~mm}$ long. A small, indistinct genital primordium is situated ventrally in the posterior part of the body (Fig. 1G,H).

\section{Third-stage larvae}

These are slender, whitish, 0.717 to $0.816 \mathrm{~mm}$ long and $0.036 \mathrm{~mm}$ wide. Their cuticle appears to be almost smooth under the light microscope. Two narrow (0.003 mm wide) cuticular alae extend along the entire body length. A pair of minute conical deirids is present $0.180 \mathrm{~mm}$ from the anterior extremity. The cephalic end is rounded and the mouth is provided with 2 small lateral, anteriorly directed sclerotized teeth. Behind each tooth is a sclerotized apparatus, which is situated at the level of the anterior end of the oesophagus and which appears bifurcate in lateral view. The apparatus is $0.012 \mathrm{~mm}$ long and $0.015 \mathrm{~mm}$ wide. Cephalic papillae are indistinct. The oesophagus is long, slender, distinctly broader at its posterior part, and is 0.222 to $0.228 \mathrm{~mm}$ long (27 to $32 \%$ of the whole body length) and $0.024 \mathrm{~mm}$ wide at the posterior part. The nerve ring and the excretory pore are 0.084 to $0.105 \mathrm{~mm}$ and 0.123 to $0.141 \mathrm{~mm}$, respectively, from the anterior extremity. The intestine is straight and narrow and contains numerous granules. The rectum is a hyaline tube and rectal glands are indistinct. The tail is conical, 0.063 to $0.075 \mathrm{~mm}$ long, bearing a distinct small cuticular spike on its tip. The length of the tail represents $9 \%$ of the total body length. A small oval genital primordium is located ventrally, 0.231 to $0.240 \mathrm{~mm}$ from the posterior extremity (Fig. 1E).

The morphology of both the second- and third-stage larvae seems to be identical with that of the corresponding larval stages of other congeneric species (Anguillicola crassus, A. novaezelandiae, A. globiceps) (Wang and Zhao 1980, Petter et al. 1989, Moravec et al. 1993, 1994) but the measurements, especially those of the $L_{2}$, are slightly smaller. In the $L_{2}$ it may be partly because only fixed larvae (contracted) were measured. However, live $\mathrm{L}_{2}$ of $A$. papernai appeared more slender, and they moved more 'elegantly' and vigorously than those of $A$. crassus.

\section{Laboratory experiments with European eels and copepods}

The first recorded intermediate hosts of Anguillicola papernai are the unidentified South African copepods used in this study and as well as the European copepods Thermocyclops cf. crassus and Mesocyclops leuckarti, all of which serve as suitable intermediate hosts as the nematode larvae develop to the infective stage. That the larvae are indeed infective was proven by infection and recovery of adult nematodes from the European eels. One of the 2 individuals infected with $\mathrm{L}_{3}$ within the copepods from South Africa and killed at 360 dpi) turned out to be uninfected. The second, however, killed at $416 \mathrm{dpi}$, contained 3 dead worms (2o, $10^{7}$ ). In addition, in the fifth month pi $L_{2}$, which were infective to European copepods and then to eels as proven by transmission experiments, were found on the bottom of the aquarium in which these 2 individuals had been kept.

The usefulness of the European copepods as intermediate hosts has been proven by infecting an eel with experimentally infected copepods. At 131 dpi when the eel was killed, its swim bladder contained 5 gravid females, 4 male worms and numerous eggs $\left(\mathrm{L}_{2}\right)$. In a second experiment using the European copepods, 2 European eels were infected with known numbers of $\mathrm{L}_{3}$ liberated from the copepods. One eel (No. 2) was infected with 20 larvae and another (No. 3), that died $7 \mathrm{~d}$ after infection, with 9 larvae. In this individual the larvae obviously had not yet reached the wall of the swim bladder and could not be found. The other one was killed 275 dpi and harboured 4 female worms, a single live male, a dead male and numerous $\mathrm{L}_{2}$ (eggs).

It is theoretically possible that the nematodes, if introduced into Europe or North America, could spread through the eel populations following the colonization pattern of Anguillicola crassus. Thus far, 
none of the 4 eel species occurring in southern and eastern Africa (Skelton 1993) is fished commercially, and probably no infected African eels have been brought to Europe or to other continents. In South Africa only a few fishermen fish for eel in the coastal parts of the rivers leading into the Indian Ocean. In addition, it is unknown whether all 4 African eel species may be suitable hosts of $A$. papernai. The 2 Madagascar mottled eels examined in this study were negative, but no conclusions should be drawn from this preliminary result. In Australia, A. australiensis only seems to parasitise in Anguilla reinhardtii while Anguillicola novaezelandiae has only been found in Anguilla australis (Moravec \& Rohde 1992, Kennedy 1994), suggesting that, unlike A. crassus, some species of Anguillicola may be host-specific. Anguillicola novaezelandiae was introduced into Lake Bracciano in Italy in the early 1980s but did not spread. It was eventually replaced by $A$. crassus which had invaded the lake in the 1990s (Moravec et al. 1994). A. novaezelandiae has demonstrated that it is able to reproduce in Anguilla anguilla in a closed habitat but did not behave like a colonizing species and could not compete with A. crassus in this small lake. Similarly, despite being capable to parasitise and reproduce in European eels, A. papernai might also not be able to compete with A. crassus in the field. Moreover, the likelihood of becoming introduced into a water-body that is free from A. crassus is ever-decreasing due to the rapid and continuous colonization of the latter species (Barse \& Secor 1999, Evans \& Matthews 1999, Maamouri et al. 1999).

On the other hand, in South Africa, Mozambique and Madagascar attempts are currently being made to use the last untouched eel resources in the world for commercial fishing and aquaculture (L. Ter Morshuizen pers. comm.). In this context we would like to strongly recommend that no live eels from Europe, Asia or elsewhere should ever be imported to southern Africa. In addition to Anguillicola crassus, other pathogenic parasites and diseases of eels (see for instance, Buchmann et al. 1987) might be imported.

Acknowledgements: The help of Mr. Denzil Radloff, of East London, whose intimate knowledge of the local conditions and who caught eels when no eels were to be found, is gratefully acknowledged. Thanks are also due to Mrs. Bärbel Seufert-Dausmann, Mrs. Cornelia Haug, Mr. Frankie Thielen, Mr. Felix Reitze and Mr. W. Send and Mr. V. Zibat (Electron Microscopical Laboratory of the University Karlsruhe) for technical assistance. Dr. Bernd Sures has also supported the investigation by various activities. The study was funded by the Foundation for Research Development and the Medical University of Southern Africa, by the 'Deutsche Forschungsgemeinschaft', and partly by grant no. 524/03/0061 from the Grant Agency of the Academy of Sciences of the Czech Republic.

\section{LITERATURE CITED}

Barker DE, Marcogliese DJ, Cone DK (1996) On the distribution and abundance of eel parasites in Nova Scotia: local versus regional patterns. J Parasitol 82:697-701

Barse AM, Secor DH (1999) An exotic nematode parasite of the American eel. Fisheries 24:6-10

Buchmann K, Mellegard S, Køie M (1987) Pseudodactylogyrus infections in eel: a review. Dis Aquat Org 3:51-57

Cardoso E M, Saraiva A M (1998) Distribution and seasonal occurrence of Anguillicola crassus (Nematoda, Dracunculoidea) in the European eel Anguilla anguilla L. from rivers of north Portugal. Bull Eur Assoc Fish Pathol 18: $136-139$

Chabaud AG (1989) Keys to the genera of the Order Spirurida. Part 1. Camallanoidea, Dracunculoidea, Gnathostomatoidea, Physalopteroidea, Rictularioidea and Thelazioidea. In: Anderson RC, Chabaud AG, Willmott S (eds) CIH Keys to the nematode parasites of vertebrates, Part 3. Commonwealth Agricultural Bureaux, Farnham Royal

Cone DK, Marcogliese DJ, Watt WD (1993) Metazoan parasite communities of yellow eels (Anguilla rostrata) in acidic and limed rivers of Nova Scotia. Can J Zool 71:177-184

Dell A, Haslam SM, Morris HR, Khoo KH (1999) Immunogenic glycoconjugates implicated in parasitic nematode diseases. Biochem Biophys Acta 1455:353-362

Evans DW, Mathews MA (1999) Anguillicola crassus (Nematoda, Dracunculoidea); first documented record of this swim bladder parasite of eels in Ireland. J Fish Biol 55: 665-668

Kelly CE, Kennedy CR, Brown J A (2000) Physiological status of wild European eels (Anguilla anguilla) infected with the parasitic nematode, Anguillicola crassus. Parasitology 120:195-202

Kennedy CR (1994) The distribution and abundance of the nematode Anguillicola australiensis in eels Anguilla reinhardtii in Queensland, Australia. Folia Parasitol 41:279-285

Kennedy CR (1995) Richness and diversity of helminth communities in tropical eels Anguilla reinhardtii in Queensland, Australia. Parasitology 111:233-245

Kennedy CR, Fitch DJ (1990) Colonisation, larval survival and epidemiology of the nematode Anguillicola crassus, parasitic in the eel, Anguilla anguilla, in Britain. J Fish Biol 36:117-131

Kennedy CR, Berrilli F, Di Cave D, De Liberato C, Orecchia P (1998) Composition and diversity of helminth communities of eels Anguilla anguilla in the river Tiber: long-term changes and comparison with insular Europe. J Helminthol 72:301-306

Kirk RS, Morritt D, Lewis JW, Kennedy CR (2002) The osmotic relationship of the swim bladder nematode Anguillicola crassus with seawater eels. Parasitology 124:339-347

Knopf K, Würtz J, Sures B, Taraschewski H (1998) Impact of low water temperature on the development of Anguillicola crassus in the final host Anguilla anguilla. Dis Aquat Org 33:143-149

Knopf K, Naser K, van der Heijden MHT, Taraschewski H (2000) Humoral immune response of European eel Anguilla anguilla experimentally infected with Anguillicola crassus. Dis Aquat Org 42:61-69

Lefèbvre F, Schuster T, Münderle M, Hine M, Poulin R (2004) Anguillicolosis in the short-finned eel Anguilla australis: epidemiology and pathogenicity. NZ J Mar Freshw Res 38: 577-583

Maamouri F, Gargouri M, Ould Daddah M, Bouix G (1999) 
Occurrence of Anguillicola crassus (Nematode, Anguillicolidae) in the Ichkeul lake (Northern Tunisia) Bull Eur Assoc Fish Pathol 19 : 17-19

Marcogliese DJ, Cone DK (1996) On the distribution and abundance of eel parasites in Nova Scotia: influence of pH. J Parasitol 82:389-399

Moravec F, Rohde K (1992) Three species of nematodes from the superfamily Dracunculoidea from Australian fishes. Acta Soc Zool Bohemoslov 56:187-195

Moravec F, Taraschewski H (1988) Revision of the genus Anguillicola Yamaguti 1935 (Nematoda: Anguillicolidae) of the swim bladder of eels, including descriptions of two new species, A. novaezelandiae sp. n. and A. papernai sp. n. Folia Parasitol 35:125-146

Moravec F, Di Cave D, Orecchia P, Paggi L (1993) Studies on the development of Anguillicola crassus Kuwahara, Niimi et Itagaki, 1974 (Nematoda: Dracunculoidea) in the intermediate host. Folia Parasitol 40:39-48

Moravec F, Di Cave D, Orecchia P, Paggi L (1994) Present occurrence of Anguillicola novaezelandiae (Nematoda: Dracunculoidea) in Europe and its development in the intermediate host. Folia Parasitol 41:203-208

Moravec F, Boomker J, Taraschewski H (2000) Paraquimperia africana n. sp. (Nematoda: Quimperiidae), a new intestinal parasite of eel Anguilla mossambica Peters, in South Africa. J Parasitol 86:113-117

Nagasawa K, Kim YG, Hirose H (1994) Anguillicola crassus and Anguillicola globiceps (Nematoda: Dracunculoidea) parasitic in the swim bladder of eels (Anguilla japonica and A. anguilla) in East Asia. Folia Parasitol 41:127-137

Neumann W (1985) Schwimmblasenparasit Anguillicola bei Aalen. Fischer Teichwirt 11:322

Ogden CG (1969) A revision of the genus Heliconema Tra-

Editorial responsibility: Wolfgang Körting,

Hannover, Germany vassos, 1919, Physalopteridae (Nematoda). J Nat Hist 3: 423-431

Petter AJ, Fontaine YA, Le Belle N (1989) Étude du dévelopment larvaire de Anguillicola crassus (Dracunculoidea, Nematoda) chez un Cyclopidae de la région parisienne. Ann Parasitol Hum Comp 65:28-31

Skelton P (1993) A complete guide to the freshwater fishes of South Africa. Southern Book Publishers, Johannesburg

Sures B, Knopf K, Würtz J, Hirt J (1999) Richness and diversity of parasite communities in European eels (Anguilla anguilla) of the river Rhine, Germany with special reference to helminth parasites. Parasitology 119:323-330

Taraschewski H, Moravec F, Lamah T, Anders K (1987) Distribution and morphology of two helminths recently introduced into European eel populations: Anguillicola crassus (Nematoda, Dracunculoidea) and Paratenuisentis ambiguus (Acanthocephala, Tenuisentidae). Dis Aquat Org 3: 167-176

Taraschewski H, Renner C, Mehlhorn H (1988) Treatment of fish parasites. 3. Effect of levamisole-HCI, metrifonate, fenbendazole and ivermectin on Anguillicola crassus (nematodes) pathogenic in the air bladder of eels. Parasitol Res 74:281-289

Thomas K, Olivier F (1992) Population biology of Anguillicola crassus in the final host Anguilla anguilla. Dis Aquat Org 14:163-170

Wang P, Zhao Y (1980) Observations on the life history of Anguillicola globiceps (Nematoda: Anguillicolidae). Acta Zool Sin 26:243-249

Würtz J, Taraschewski H (2000) Histopathological changes in the swim bladder wall of the European eel Anguilla anguilla due to infections with Anguillicola crassus. Dis Aquat Org 39:121-134

Submitted: April 2, 2002; Accepted: September 8, 2004 Proofs received from author(s): January 21, 2005 